\title{
APARATO PARA CONDUÇÃO DE EXPERIMENTOS EM LABORATÓRIO DOS EFEITOS DO CAMPO MAGNÉTICO SOBRE ORGANISMOS AQUÁTICOS.
}

\author{
Carlos Geraldo Barreto GONÇALVES ${ }^{1}$ \\ Carmen MEDEIROS ${ }^{2}$ \\ Jardenes de OLIVEIRA JUNIOR ${ }^{3}$ \\ Dalasiel LIMA ${ }^{3}$
}

\begin{tabular}{|l|}
\hline Recebido em: $30 / 06 / 2009$ \\
\hline Aceito em: $12 / 11 / 2009$ \\
\hline
\end{tabular}

\section{RESUMO}

O presente trabalho enfoca a descrição e o processo construtivo de um aparato simples e de baixo-custo capaz de gerar um campo magnético que pode ser utilizado para expor organismos aquáticos para testes, em condições de laboratório, e a concepção de um software dedicado para aquisição automática de dados durante os experimentos. O aparato consiste de um par de bobinas de Helmholtz de 15AWG com 60 $\mathrm{cm}$ de diâmetro. Cada bobina formada por 46 espiras de fio de cobre 15AWG (secção transversal de $1,5 \mathrm{~mm}^{2}$; resistência linear=0,010 ohms) envernizado sobrepostas, de forma a ocupar uma extensão de $2 \mathrm{~cm}$ e capaz de suportar uma corrente máxima de 13A. O par de bobinas é alimentado por uma fonte de corrente contínua variável, permitindo gerar campo magnético de 0 a $300 \mu \mathrm{T}$. O aparato mostrou-se adequado para condução de experimento sobre o efeito do campo magnético sobre organismos aquáticos de pequeno e médio porte e tem a vantagem de poder ser construído artesanalmente a baixo custo e de fácil manuseio e com uma perspectiva positiva de aplicação de um software para sua automatização.

Palavras-chave: Bobinas de Helmholtz, campo magnético, organismos aquáticos, software dedicado

\section{APPARATUS FOR THE CONDUCTION OF LABORATORY EXPERIMENTS ON THE EFFECTS OF THE MAGNETIC FIELD UPON AQUATIC ORGANISMS}

\section{ABSTRACT}

This paper focus on the specification and the construction of a simple, low-cost apparatus to produce a homogeneous magnetic field to expose small to medium aquatic organisms in laboratory conditions, and on the concept of a dedicated software that could be used for data acquisition and storage during those tests. The apparatus consisted of a pair of Helmholtz coils with a diameter of $60 \mathrm{~cm}$. Each one was made by 46 loops of copper wire 15AWG (transversal section of $1.5 \mathrm{~mm}^{2}$; linear resistance $=0.010 \mathrm{ohms}$ ) varnished and overlapped, mounted in a way to occupy an extension of $2 \mathrm{~cm}$, and able to support a maximum current of $13 \mathrm{~A}$. The pair of coils was feed by a variable DC source allowing the generation of a magnetic field from 0 to $300 \mu \mathrm{T}$. The apparatus demonstrate to be adequated for the conduction of experiments on the effect of the magnetic field upon small to medium-size aquatic organisms, having the advantage that it is homemade, low-cost and easy-handled and having a positive perspective of became automitized with a software application.

Keywords: Helmholtz coils, magnetic field, aquatic organisms, dedicated software.

Contatos: 1 Mestrando Programa de Pós-graduação em Oceanografia, Departamento de Oceanografia - UFPE, Av. Arquitetura S/N, Campus Universitário, 50740-550 Recife - PE.

${ }^{2}$ Laboratório de Oceanografia Física Estuarina e Costeira, Departamento de Oceanografia - UFPE, Av. Arquitetura S/N, Campus Universitário, 50740-550 Recife - PE.

${ }^{3}$ Estagiário do Laboratório de Oceanografia Física Estuarina e Costeira, Departamento de Oceanografia - UFPE, Av. Arquitetura S/N, Campus Universitário, 50740-550 Recife - PE 


\section{INTRODUÇÃO}

A presença e o sucesso de um organismo ou de um grupo de organismos dependem de um complexo de condições ambientais como pH, salinidade, luminosidade, elementos climáticos (ventos, chuva, pressão, temperatura e umidade), correntes superficiais e profundas, concentração de sais dissolvidos na água, etc. Os organismos individuais não só se adaptam ao ambiente físico, como também, através da sua ação conjunta nos ecossistemas, ao ambiente geoquímico para atender às suas necessidades biológicas. Desta forma, as comunidades de organismos e seus ambientes de entrada e saída desenvolvem-se em conjunto, como os ecossistemas (BAPTISTA NETO; PONZI; SICHEL, 2004).

O campo geomagnético é um componente abiótico com o qual os seres vivos interagem permanentemente e que tem estado presente desde muito antes do surgimento da vida em nosso planeta. A interação complexa, com uma dinâmica temporal não repetitiva, tem levado os seres vivos a tomarem diferentes caminhos evolutivos (ACOSTA-AVALOS et al., 2000). A percepção de sinais do meio por microrganismos e animais superiores tem levado ao desenvolvimento de diferentes mecanismos ao longo do tempo, que são responsáveis pela sobrevivência das espécies, como a orientação e a navegação, contribuindo para o processo de seleção natural (SKILES, 1985).

O magnetismo é atualmente um dos campos de pesquisa mais férteis e mais ativos na física da matéria condensada. Do ponto de vista da pesquisa básica, os fenômenos magnéticos representam uma aplicação complexa de mecânica quântica, física estatística e eletromagnetismo, atraindo assim a atenção de físicos teóricos e experimentais (REZENDE, 2000). As interações do campo magnético com os seres vivos abrangem um amplo espectro de questões, que vão desde o mistério das migrações de peixes e outros animais, até o estudo da física quântica em cristais magnéticos de proporções nanométricas presentes no interior de vários microorganismos (LINS DE BARROS \& ESQUIVEL, 2000).

Tendo em vista que os oceanos e mares correspondem a cerca de $72 \%$ da superfície terrestre, que a vida começou na água, e que os organismos vivos e seu ambiente estão inseparavelmente inter-relacionados (ODUM, 1988), fica evidente a importância de se buscar entender como o campo magnético terrestre e campos magnéticos artificiais influenciam os organismos aquáticos.

A despeito de sua importância, o campo magnético é ainda um fator ambiental pouco estudado relativamente aos demais fatores abióticos. Esse panorama é ainda mais desfavorável, quando se considera os trabalhos que incluem a influência do campo magnético aplicado no comportamento dos organismos marinhos.

Dentre os principais tópicos de pesquisa atual em magnetismo, pode-se destacar a influencia deste nos sistemas orgânicos (REZENDE, 2000). Este fenômeno físico-biológico necessita de estudos mais aprofundados para se compreender um pouco mais a vida em nosso planeta, sobretudo no ambiente marinho.

$\mathrm{Na}$ literatura existem poucos registros de dispositivos específicos para testes de efeitos magnéticos em animais marinhos. Por exemplo, SHCHERBAKOV et al., 2007, utilizaram uma configuração simples, e com dados incipientes referentes ao seu dimensionamento, em sua estrutura experimental bem diferente da exposta neste trabalho. Seu par de bobinas dispostas no sentido leste-oeste do aquário foram desenvolvidas para um arranjo que condicionava os peixes através de punições com choques elétricos, quando os organismos não respondiam ao campo magnético.

A falta de equipamentos específicos para a condução de testes experimentais de comportamento com animais aquáticos de pequeno e médio portes instigou a idealização e construção de um sistema para tal. O aparato desenvolvido é simples e de baixo custo, e consiste de um par de bobinas confeccionadas manualmente as quais foram dimensionadas de modo a permitir a geração de campo magnético com intensidade 
GONÇALVES et. al. Aparato para condução de experimentos em laboratório dos efeitos do campo magnético sobre organismos aquáticos.

variável de 0 a $300 \mu \mathrm{T}$. No presente trabalho foi medido o range da densidade do fluxo magnético das bobinas citadas, com uma perspectiva de implementação de um software microcontrolador com função de automatizar as atividades do par de bobinas de Helmholtz.

\section{PRINCIPIOS E FUNDAMENTOS}

\section{Magnetismo}

O magnetismo foi descoberto pelos gregos há cerca de 2000 A.C anos quando, em Magnésia, Ásia menor, foi encontrado um tipo de pedra que era atraída pelo ferro, e que devido ao local de sua descoberta, recebeu o nome de magnetita. Posteriormente verificou-se que esta pedra, quando suspensa por um fio, alinhava na direção norte-sul, e passou-se a chamá-la de pedra indicadora ou pedra-ímã. A magnetita é um ímã natural capaz de atrair materiais magnéticos.

Para estabelecer as regras que explicam como os ímãs interagem entre si, atribuem-se polaridades Norte (N) e Sul (S) aos seus extremos. Para tanto, o ímã é suspenso por um cabo que o permita girar livremente. A extremidade do ímã que apontar para o pólo norte geográfico é chamada de pólo Norte do ímã. O fato de um ímã livre tender sempre a se alinhar com o campo magnético da terra é um indício de que há algumas leis definidas que governam os efeitos magnéticos (Fig. 1). São as leis da atração e da repulsão, análogas às leis de atração e repulsão das cargas elétricas, com exceção das polaridades $\mathrm{N}$ e $\mathrm{S}$ que são usadas ao invés de negativo e positivo. As leis estabelecem que: Pólos de mesmo nome se repelem e pólos de nomes diferentes se atraem (MILEAF, 1982).

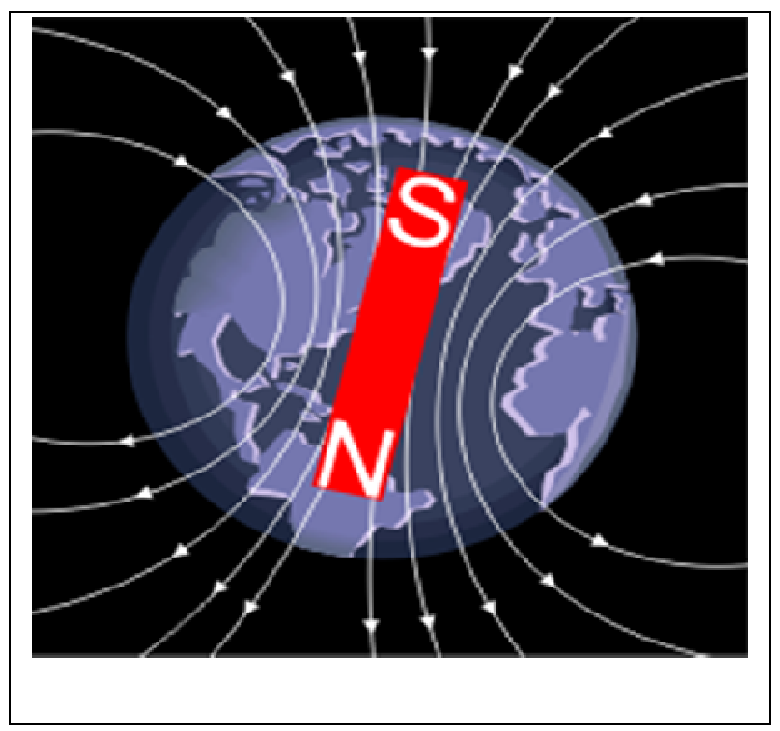

FONTE: commons.http//:www.wikimedia.org/wiki/File:CampoMagnetic.br

Figura 1. Representação esquemática do campo magnético terrestre.

A atração e repulsão dos pólos magnéticos indicam que eles originam forças que causam essas ações. E elas não existem apenas nos pólos. A força magnética realmente circunda o ímã ao redor de seu campo. Pode-se então observar isto movendo uma bússola em torno de uma barra imantada. Em cada ponto das proximidades da barra imantada, uma das extremidades da bússola apontará para o pólo oposto da barra. 0 campo magnético é formado por linhas de força que saem do pólo $\mathrm{N}$, espalham-se por todo o espaço e entram pelo pólo $\mathrm{S}$. Essas linhas nunca se cruzam e a distância entre elas aumenta à medida que nos afastamos do ímã. Quanto maior o número de linhas de força e quanto menor a distância entre elas, mais intenso será o campo magnético.

\section{Eletromagnetismo}

Em 1819, o cientista dinamarquês Hans Cristian Orested descobriu a relação entre 
- magnetismo e a corrente elétrica. Ele observou que uma corrente elétrica, ao atravessar um condutor, produzia um campo magnético ao redor do condutor (Fig. 2) e que a intensidade desse campo dependia da intensidade da corrente que o gerava. Uma corrente alta produzia inúmeras linhas de força que se distribuíam até regiões bem distantes do fio, enquanto que uma corrente baixa produzia poucas linhas próximas ao fio (GUSSOW, 2004).

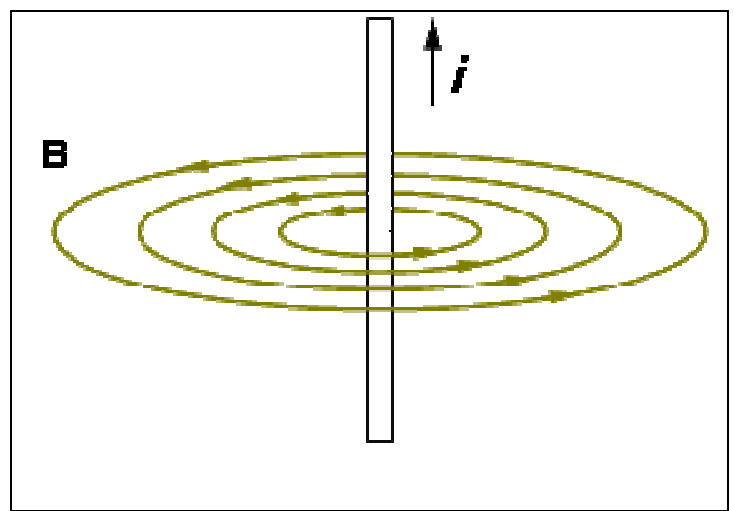

Figura 2. Campo magnético ao redor de um condutor percorrido por uma corrente elétrica.

\section{Campo formado por uma bobina}

Forma-se uma bobina de fio condutor quando se faz mais de um laço ou espira com o mesmo. O fato de se curvar um condutor reto de modo a formar um laço simples traz duas consequências: (1) as linhas de campo magnético ficam mais densas dentro do laço, embora o número total de linhas seja o mesmo que para o condutor reto e a (2) todas as linhas dentro de um laço somam no mesmo sentido. A polaridade magnética da bobina pode ser determinada aplicando-se a regra da mão direita (Fig. 3). Segurando-se a bobina com os dedos da mão direita, dobrados no sentido do fluxo da corrente através da bobina, o polegar apontará para o pólo Norte da bobina (GUSSOW, 2004).

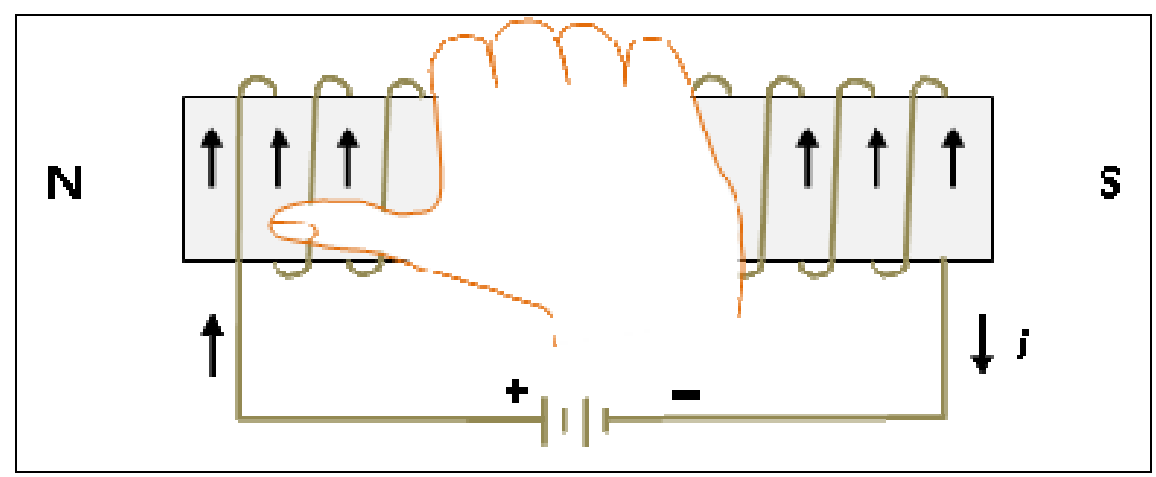

Figura 3. Regra da mão direita para determinação de polaridade do campo magnético de bobinas ou solenóides.

\section{Bobina Circulares e de Helmholtz}

Arranjos de bobinas circulares dispostas alinhadas, quando percorridos por uma corrente elétrica, geram um campo magnético ao longo do eixo-z que passa pelos seus centros. A corrente que circula nas bobinas possui o mesmo sentido, sendo o campo magnético resultante entre as bobinas igual à soma vetorial das contribuições de cada uma delas. A conformação do campo gerado dependerá das características das bobinas e de suas posições relativas. As linhas de campo magnético para duas bobinas circulares iguais alinhadas são representadas na Figura 4. 
GONÇALVES et. al. Aparato para condução de experimentos em laboratório dos efeitos do campo magnético sobre organismos aquáticos.

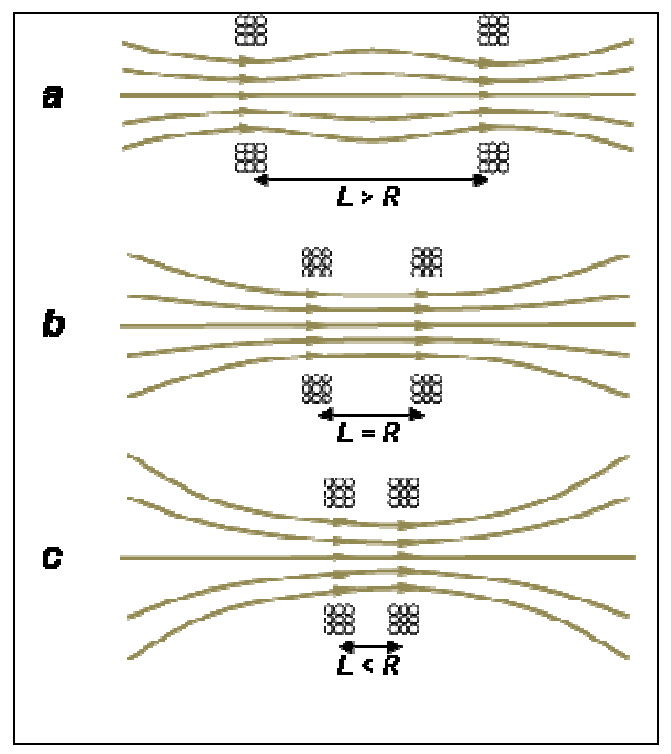

Figura 4. Representação das linhas de campo magnético entre duas bobinas circulares iguais, para diferentes relações entre a distancia $L$ entre elas e seu raio $R$ : (a) $\boldsymbol{L}>\boldsymbol{R}$; (b) $\boldsymbol{L}=\boldsymbol{R}$ e (c) $\boldsymbol{L}<\boldsymbol{R}$. TOGINHO FILHO \& LAURETO (2008).

Quando a distancia ente as bobina supera o valor de seu raio (Fig. 4a), as linhas do campo apresentam-se mais expandidas no ponto médio relativas aos pontos das bobinas e quando é inferior (Fig. 4c), mais comprimidas.

A bobina de Helmholtz corresponde à condição $\boldsymbol{L}=\boldsymbol{R}$ (Fig. 4b). Nesta configuração, as bobinas produzem uma região de campo magnético uniforme entre as bobinas indicada pelas linhas de campo aproximadamente paralelas (TOGINHO FILHO \& LORETO, 2008) e que pode ser usado como campo de referencia. O valor do campo magnético $\boldsymbol{B}$ no ponto médio entre as bobinas pode ser calculado pela expressão:

$$
B=\frac{8 \mu I N}{5 \sqrt{5 R}}
$$

onde: $\boldsymbol{B}$ indica o valor do campo magnético em Tesla; $\boldsymbol{N}$ é o número de espiras; $\boldsymbol{I}$ é a intensidade de corrente; $\boldsymbol{R}$ é o raio da bobina e $\boldsymbol{\mu}$ é a constante de permeabilidade magnética do vácuo.

\section{Aparato para geração de campo magnético de intensidade variá-vel}

\section{Concepção}

Os efeitos que o campo geomagnético produz nos sistemas biológicos foram comprovados desde a década de 70, quando foram descobertas bactérias que respondem diretamente a este campo magnético, se deslocando na direção das linhas de campo (BLAKEMORE, 1975) embora haja registros de estudos anteriores. A partir de então muitos outros organismos foram estudados. São sensíveis ao campo geomagnético espécies de tartarugas marinhas, aves, peixes, mamíferos, anfíbios, insetos, crustáceos e moluscos (WILTSCHKO \& WILTSCHKO, 1995).

As pesquisas relacionadas com magnetismo em animais marinhos são fundamentadas em diversos modelos de percepção magnética, intermediada por receptores biológicos específicos. Vários modelos nos quais tais receptores podem mediar informação magnética têm sido desenvolvidos (THALAU, 2007). O modelo da transdução ferromagnética, baseado na presença de nanopartículas magnéticas, é o modelo de magnetorecepção mais bem aceito atualmente (ACOSTA-AVALOS et al., 2000). Este sistema agiria como um magnetômetro biológico detectando a intensidade magnética local (LOHMANN AND JOHNSEN, 2000).

Em se tratando de animais marinhos como peixes, alguns exemplos clássicos confirmam a relação do magnetismo terrestre com o sistema de percepção por parte 
desses animais. No caso dos salmões (família salmonidae), peixes de valor comercial, desportivo e gastronômico considerável (ROGADO et al., 2005) existem alguns neurônios no seu nervo trigerminal que respondem a mudanças na intensidade no campo magnético aplicado, como ocorre com a espécie Oncorhynchus mykiss. Finas ramificações do nervo estudado aproximam-se de células magnetoreceptoras com magnetita na narina do animal (WALKER et al., 1997). A proximidade da associação entre o nervo receptor magnético e as células envolvidas na magnetorecepção, indica que há uma conexão funcional entre essas estruturas biológicas, fazendo com que estes peixes exibam padrões de resposta ao campo magnético, acompanhando inclusive, o deslocamento desse campo (WALKER \& GREEN, 2000).

Para conduzir estudos controlados de laboratório que permitam investigar melhor a função dessas estruturas e a resposta ao campo magnético, é necessário produzir um campo magnético uniforme de baixa intensidade ao qual os organismos teste possam ser submetidos. Quando o volume a ser submetido ao campo é pequeno, como no caso de exposição de bactérias e outros organismos muito pequenos, solenóides podem ser empregados, pois os aquários ou caixas testes colocados no centro do mesmo ficam expostos a campos homogêneos. Por outro lado se os organismos testes são de pequeno a médio porte, como no caso de camarões, alguns peixes, a construção de solenóides que comportem aquários de 10-100 litros e de estrutura para deslocar os aquários para o interior dos mesmos, se faz pouco prática e tem um custo relativamente alto.

O acondicionamento dos espécimes teste (i.e. camarões e pequenos peixes) requeria um aquário de cerca de $50 \mathrm{~L}$ de capacidade, de difícil manuseio. Assim na concepção do sistema, considerou-se que o mesmo deveria permanecer estacionário, e que a geração do campo se daria a partir de um par de bobinas circulares idênticas, de mesmo raio e número de espiras, na configuração de Helmholtz, que poderiam ser posicionadas em cada lado da maior dimensão do aquário.

As aplicações da bobina de Helmholtz são várias, dentre as quais podemos citar: a determinação das componentes vertical e horizontal do campo magnético terrestre; a anulação do campo magnético terrestre em determinado volume e estudo de efeitos magnetobiológicos (ROBERT, 2003).

\section{Construção das Bobinas}

O primeiro passo consistiu em buscar um suporte cilíndrico para acomodação dos fios no enrolamento que deveria ter um diâmetro de cera de $60 \mathrm{~cm}$. No comércio não foram encontradas tubulações de material não metálico com essas dimensões, verificando-se também que as oficinas locais especializadas em tornearia mecânica em geral também não fabricavam cilindros com diâmetros superiores a $30 \mathrm{~cm}$ de diâmetro. Assim, os cilindros para montagem das bobinas foram obtidos a partir de cortes em um tonel plástico de PE-HD de $230 \mathrm{~L}$ e $100 \mathrm{~cm}$ de altura, utilizado na armazenagem de detergentes, cloro, etc., facilmente encontrados em depósitos de materiais reciclados. Esses tonéis apresentam paredes suficientemente rígidas e um setor central cilíndrico, permitindo a extração de dois anéis de $50 \mathrm{~cm}$ de largura. Os anéis obtidos foram então limpos, lixados e pintados, para proporcionar um bom acabamento nos cortes dos mesmos.

Para fixação dos cilindros os mesmos foram circunscritos em quadrados $(80 \mathrm{~cm} \times$ $80 \mathrm{~cm}$ ) vazados em compensado de $15 \mathrm{~mm}$ e apoiados em quatro bases triangulares de $30 \mathrm{~cm}$ de lado e $30 \mathrm{~mm}$ de espessura. Cada quadrado foi serrado com serra tipo tico-tico, tendo como medida a circunferência de cada bobina. As folhas de compensado foram então revestidas com fórmica branca, visando assegurar sua durabilidade.

A superfície externa do cilindro foi revestida por uma camada de fita de auto-fusão para melhorar a acomodação do fio e evitar acúmulo de umidade. A fita auto-fusão empregada, contem em sua composição borracha de etileno-propileno (EPR), e suporta temperatura de até $105^{\circ} \mathrm{C}$ e classes de tensões de 600 a 69.000 volts (especificação do fabricante). Foi preciso para isto apenas 1 rolo de $19 \mathrm{~mm} \times 2 \mathrm{~m}$ e espessura de 0,76 $\mathrm{mm}$. No ponto médio dos pares de bobinas, uma base de granito polido foi colocada apoiada 
GONÇALVES et. al. Aparato para condução de experimentos em laboratório dos efeitos do campo magnético sobre organismos aquáticos.

em um bloco de cimento. Um fino tapete de borracha foi então colocado sobre o granito, para melhor apoiar o aquário teste.

Cada bobina foi formada por 46 espiras de fio de cobre 15AWG (secção transversal de $1,5 \mathrm{~mm}^{2}$; resistência linear $=0,010 \mathrm{ohms}$ ) envernizado sobrepostas, de forma a ocupar uma extensão de $2 \mathrm{~cm}$, capaz de suportar corrente máxima de 13A. As bobinas foram ligadas em série de modo que a corrente elétrica que atravessava as mesmas possuía mesma intensidade e produzia um campo magnético de características semelhantes. Foi tomado o cuidado de observar que o sentido da corrente entrando e saindo das bobinas foi o mesmo, (Fig.5). A configuração do aparato é apresentada na figura 6.

Os aquários utilizados nos testes com esse aparato, tiveram dimensões de $60 \mathrm{~cm} x$ $30 \mathrm{~cm} \times 35 \mathrm{~cm}$ (comprimento $\times$ largura $\times$ altura), e foram posicionados de modo centralizado entre as bobinas de forma a mantê-las separadas a uma distância de $60 \mathrm{~cm}$. Mantendo-se uma lâmina d'água de $30 \mathrm{~cm}$, obtêm-se um volume de 54 litros, o que permitiu testes com uma população de 20 indivíduos juvenis $(8-10 \mathrm{~cm})$ de camarões Litopenaeus vannamei.

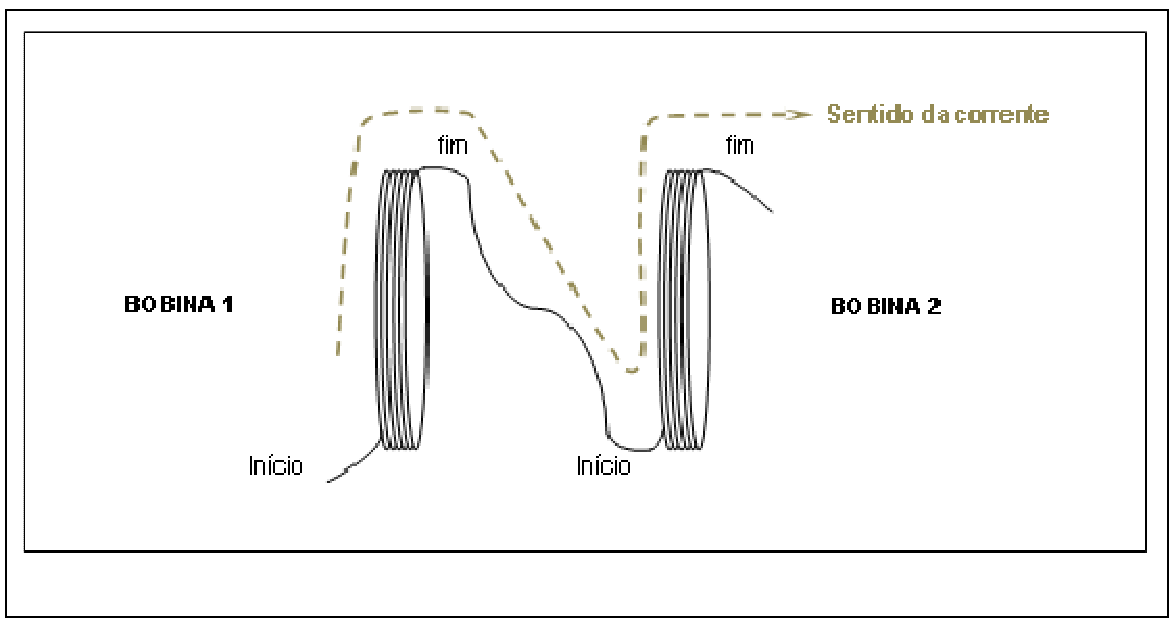

Figura 5. Arranjo superior das bobinas, indicando a ligação em série das mesmas em série (fim da bobina 1 ligado ao início da bobina 2).

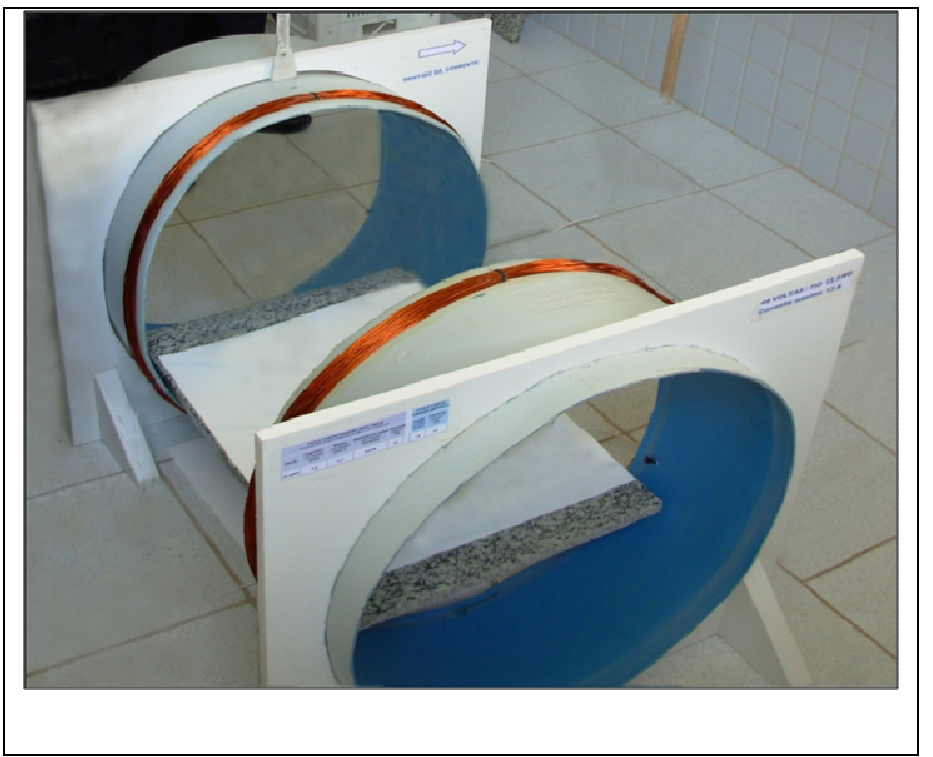

Figura 6. Bobinas de Helmholtz para geração de campo magnético e condução de experimentos magnetobiológicos. Ao centro, a base para o apoiar o aquário no qual se acondicionariam os organismos teste. 


\section{Alimentação das bobinas.}

As bobinas foram alimentadas com uma fonte digital variável DC (de tensão máxima $30 \mathrm{~V}$ e corrente máxima $5 \mathrm{~A}$ ), permitindo a obtenção de diferentes intensidades de campo, em função da intensidade de corrente aplicada (Fig. 7).

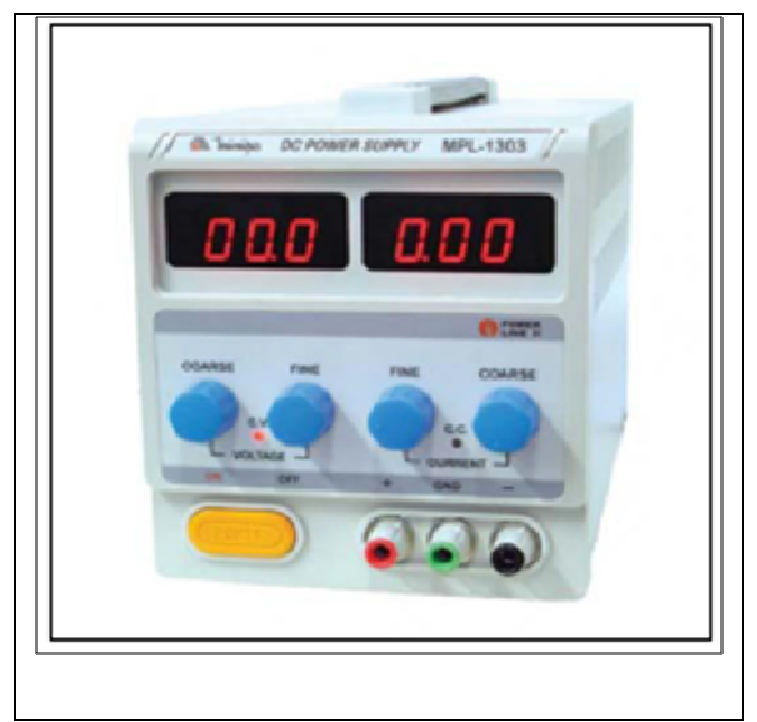

Figura 7. Fonte digital variável DC Minipa, MLP 1303(30V/3A) para alimentação das bobinas.

Esta possibilidade de variação de intensidades de campo magnético gerado permitiu a adequação aos níveis necessários aos estudos realizados - no caso desta pesquisa, a resposta de animais marinhos aos campos magnéticos de diferentes intensidades.

\section{Concepção de sistema de automação e de software dedicado}

Nos testes em laboratório, o aparato desenvolvido foi operado manualmente. No entanto para exposições de médio e longo prazo, um sistema capaz de automatizar a bateria de experimentos e a aquisição dos dados seria grandemente desejável. Com este fim, foi concebido o sistema descrito a seguir, que se encontra em fase de implementação. O sistema permite o controle da intensidade da corrente e conseqüentemente da intensidade e do sentido do campo magnético gerado e uma préprogramação do tempo de ativação/desativação das bobinas. As partes integrantes do sistema incluem hardware microcontro-lado, software desktop e banco de dados relacional (DB-Data Base), permitindo armazenar em um banco de dados informações referentes à intensidade do campo, momento e período de aplicação do campo sobre os organismos teste, bem como o armazenamento de imagens dos aquários capturadas com uma câmera digital de forma contínua ou instantânea. Isto confere maior segurança e persistência das informações relativas aos experimentos realizados e possibilita a análise dos dados e observações varias vezes.

A automação do processo se dá através de um microcontrolador, que pode ser considerado um computador de pequeno porte, encapsulado em um chip, onde existe memória de programa, memória de dados, portas de entrada e saída, timers, contadores, conversores analógico-digitais (SOUZA, 2003), este sistema é esquematizado na figura 8. A interação do pesquisador com o sistema se dá através de uma interface gráfica de usuário. Este software vem sendo desenvolvido sob paradigma da orientação a objetos explorando a tecnologia Java voltada a desktop J2SE-Java 2 Standard Edition (DEITEL \& DEITEL, 2005) e se integra ao microcontrolador através da API (Application Programming Interface) JavaComm, que permite comunicação no padrão serial. A parte final diz respeito à integração com o Banco de Dados (SILBERSCHATZ et al., 1999) através da API JDBC (Java Database Conectivity), onde as informações podem ser inseridas, apagadas, consultadas e modificadas com segurança e a qualquer tempo. 
GONÇALVES et. al. Aparato para condução de experimentos em laboratório dos efeitos do campo magnético sobre organismos aquáticos.

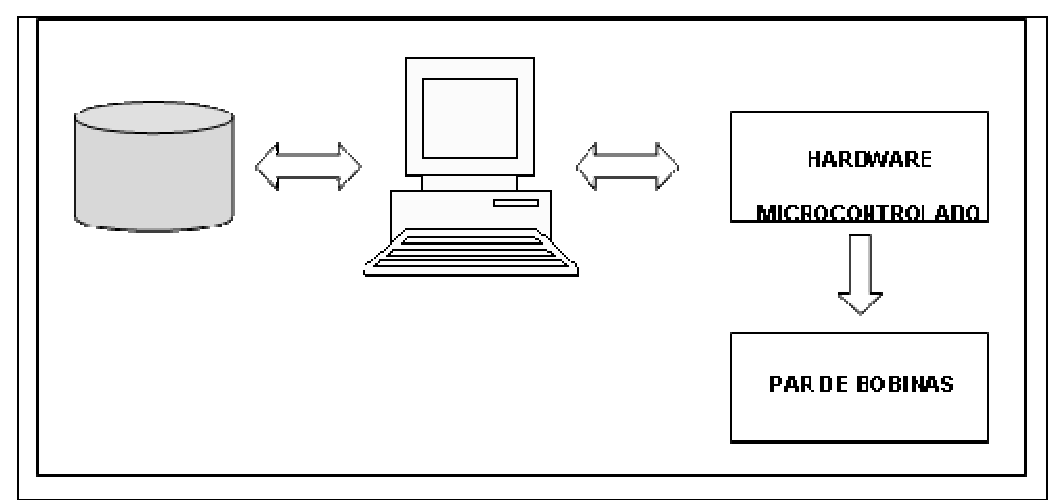

Figura 8. Esquema do sistema de automação para condução dos testes e captação de dados.

O sistema concebido é modular, com a comunicação entre hardware e software desktop sendo realizada a partir de uma porta serial (ou USB transformada para serial). A linguagem de programação Java possibilita o suporte às operações necessárias de comunicação e a construção de interfaces gráficas bastante funcionais. Como supervisor de hardware usa-se o microcontrolador PIC, mais barato que os demais que existem no mercado, e que utiliza padrão USART para comunicação serial. A arquitetura funcional do sistema é esquematizada na figura 9 e a função de cada módulo indicada na tabela 1.

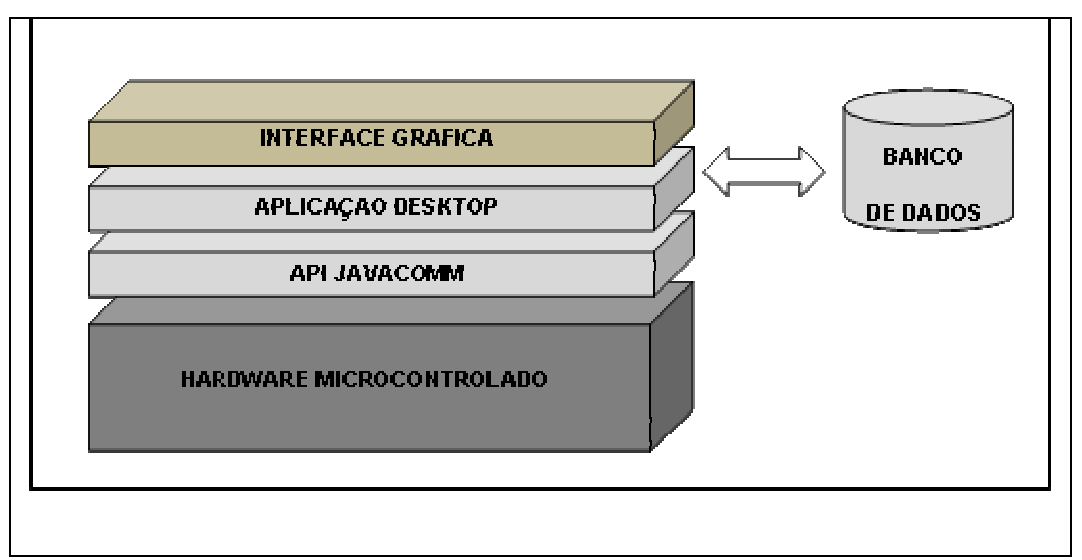

Figura 9. Esquema da arquitetura funcional do sistema computacional.

Tabela 1. Função dos módulos componentes

\begin{tabular}{|c|c|}
\hline Interface Gráfica & $\begin{array}{l}\text { Permitir a interação do usuário com o sistema de forma } \\
\text { fácil e amigável; }\end{array}$ \\
\hline Aplicação Desktop & $\begin{array}{l}\text { Interagir com o hardware microcontrolado, banco de dados } \\
\text { e a interface gráfica de usuário. }\end{array}$ \\
\hline API JavaComm & $\begin{array}{l}\text { Biblioteca Java que possui códigos que dão suporte a } \\
\text { comunicação nos protocolos RS-232 e RS- } 485 \text {, padrão } \\
\text { serial }\end{array}$ \\
\hline Hardware Microcontrolado & $\begin{array}{l}\text { Acionar o par de bobinas eletromagnéticas, no sentido e } \\
\text { intensidade de campo desejados e repassar as informações } \\
\text { sobre o campo gerado para a aplicação desktop. }\end{array}$ \\
\hline $\begin{array}{l}\text { Banco de Dados (Data } \\
\text { Base-DB) }\end{array}$ & $\begin{array}{l}\text { Armazenar os dados dos experimentos realizados, podendo } \\
\text { ser consultado em qualquer momento. }\end{array}$ \\
\hline
\end{tabular}




\section{CONSIDERAÇÕES FINAIS}

Embora bobinas de Helmholtz sejam citadas em vários experimentos de magnetobiologia e sobre o magnetismo animal, (i.e. SHCHERBAKOV et al., 2007), quase sempre uma descrição das características dos sistemas utilizados na geração do campo magnético é omitida ou fornecida de forma muito simplificada, impedindo sua duplicação. Ainda, muitos dos experimentos descritos em literatura utilizam bactérias ou outros organismos diminutos, como organismos testes, e assim os sistemas utilizados não são adequados à gama de experimentos que envolvesse organismos de pequeno e médio porte.

No presente trabalho, um sistema utilizado com sucesso para expor camarões Litopenaeus vannamei a diferentes intensidades de campo magnético em condições de laboratório, e que poderia ser igualmente utilizado para exposições de outros organismos aquáticos de pequeno e médio porte (peixes, crustáceos, moluscos, etc.), ou mesmo organismos terrestre é descrito de forma detalhada bem como indicado seu processo construtivo. O sistema descrito apresenta a vantagem de ser simples, de fácil construção, e de empregar materiais facilmente encontrados no comércio, resultando em um custo final reduzido. É de fácil manuseio e flexível, permitindo alterar a intensidade e o sentido do campo criado na faixa de 0 a $300 \mu \mathrm{T}$ e facilmente adaptável para outras intensidades de campo. Esse sistema está sendo incrementado de forma a permitir a automação da condução dos testes e da aquisição e armazenagem dos dados. A concepção desse sistema é igualmente descrita.

\section{AGRADECIMENTOS}

Nossos agradecimentos ao Prof. Daniel Acosta-Avalos, e ao Prof. José Wilson Vieira pelas valiosas sugestões e discussões.

\section{REFERÊNCIAS BIBLIOGRÁFICAS.}

ACOSTA-AVALOS, D.A.; WAJNBERG, E.; ESQUIVEL, D.M.S. e EL-JAICK, L. J. Insetos sociais: um exemplo de magnetismo animal. Revista Brasileira de Ensino de Física, v. 22, n. 3, p. 317-323, 2000.

BAPTISTA NETO, J.A.; PONZI, V.R.; SICHEL, S.E. (Ed.). Introdução a Geologia Marinha. 1a ed. Rio de Janeiro: Interciência, 2004. 279 p.

BLACKMORE, R. P. Magnetotatic Bactéria. Science, v. 190, p. 377-379, 1975.

DEITEL, H. M. e DEITEL, P. J. Java como Programar, Pearson Prentice Hall, São Paulo, 2005.

GUSSOW, MILTON. Eletricidade Básica, Makron Books, São Paulo, 2004.

LINS DE BARROS, H.G.P.L.; ESQUIVEL, D.M.S. Interação do Campo Magnético da Terra com os Seres Vivos: História da sua Descoberta. Revista Brasileira de Ensino de Física, v. 22, n. 3, p. 312 - 316, 2000.

LOHMANN, K. J. and JOHNSEN, S.The neurobiology of magnetoreception in vertebrate animals. Trends Neurosci 23: 153 -159, 2000.

MILEAF, H. Eletricidade, Martins Fontes, São Paulo, 1982.

ODUM, E.P. Ecologia. 1a ed. Rio de Janeiro: Editora Guanabara, 434 p. 1988.

REZENDE, S.M. Magnetismo na Terra Brasilis. Revista Brasileira de Ensino de Física, V. 22, n. 3, p. 293-298. 2000.

ROBERT, R. Bobina de Helmholtz. Revista Brasileira de Ensino de Física, v.25, n. 1, p.40-44. 2003.

ROGADO, L. ; ALEXANDRINO, P. ; ALMEIDA P.R.; ALVES, J.; BOCHECHAS, P.; CORTES, R.; DOMINGOS, I.; FILIPE, F.; MADEIRA, J.; MAGALHÃES F. 2005. Salmo solar salmão IN: Livro Vermelho dos Vertebrados de Portugal. CABRAL, M. J. et al. (eds). Instituto da Conservação da Natureza, Lisboa. 
GONÇALVES et. al. Aparato para condução de experimentos em laboratório dos efeitos do campo magnético sobre organismos aquáticos.

SHCHERBAKOV, D.; WINKLHOFER, M.; PETERSEN, N.; STEIDLE, J.; HILBIG, R.; BLUM, M. Magnetosensation in zebrafish. Current Biology. v. 15, n. 5. 2007.

SILBERSCHATZ, A.; KORTH, H. F.; SUDARSHAN, S. Sistema de Banco de Dados. São Paulo: Makron Books, 1999.

SKILES, D.D. The geomagnetic field: its nature, history, and biological relevance. In: Magnetite biomineralization and magnetoreception in organisms: a new biomagnetism. KIRSCHVINK, J.L.; JONES, D.L.; MACFADEN, B.J. (Eds.). New York: Plenum Press, 1985. p. 43-102.

SOUZA, D. J. Desbravando o PIC: ampliado e atualizado para 16F628A. São Paulo: Érica, 2003.

THALAU, P.; HOLTKAMP-RÖTZER, E.; FLEISSNER, G.; WILTSCHKO. Homing pigeons (Columba livia f. domestica) can use magnetic cues for locating food. SpringerVerlag, v. 94, p. 813-819, 2007.

TOGINHO FILHO, D.O.; LAURETO, E. Campo Magnético Ambiental - Bobina de Helmholtz. Catálago de Experimento do Laboratório Integrado de Física Geral. Departamento de Física. Universidade Estadual de Londrina, Junho, 2008.

WALKER, M.M.; DIEBEL, C.E.; HAUGH, C.V.; PANKHURST, P.M.; MONTGOMERY, J.C.; e GREEN, C.R. Structure and function of the vertebrate magnetic sense. Nature, $v 390, p$. 371-376, 1997.

WALKER, M.M.; GREEN, C.R. Structure, function, and use of the magnetic sense in animal. Journal of Applied Physics, v. 5, n. 5, p. 1-10, 2000.

WILTSCHKO, R.; WILTSCHKO, W. (Ed.). Magnetic Orientation in Animals. 1a ed. New York: Springer-Verlag, 1995. 225 p. 